\title{
O GÊNERO TEXTUAL CAUSO NO LIVRO DIDÁTICO DE LÍNGUA PORTUGUESA
}

\author{
Marilúcia dos Santos Domingos STRIQUER \\ Universidade Estadual do Norte do Paraná \\ Patrícia Cardoso Batista \\ Graduação - Universidade Estadual do Norte do Paraná \\ Bolsista PIBID/CAPES
}

\begin{abstract}
RESUMO: O causo é um gênero textual que tem como função sócio-comunicativa materializar a cultura popular brasileira, sendo assim, importante instrumento para preservação e disseminação da referida cultura. Nesse sentido, a equipe do PIBID/UNEP Letras/Português, campus Jacarezinho, elaborou um modelo didático e sequências didáticas sobre esse gênero e a implementou em salas de aulas dos sextos anos do ensino fundamental, de escolas da cidade de Jacarezinho/PR. Partindo, então das reflexões sobre todas essas ações didáticas, interessamo-nos em compreender como esse gênero é proposto pelo livro didático de língua portuguesa, uma vez que o livro didático é uma ferramenta pedagógica muito mais presente em salas de aulas do que trabalhos com projetos. Para tanto elegemos a obra "Tecendo linguagens" (OLIVERIA et al., 2012), destinado ao 6 ano do ensino fundamental, e nos pautamos sobre os preceitos do Interacionismo Sociodiscursivo. Os resultados apontam que o material não consegue abranger toda a complexidade textual, discursiva e sóciocomunicativa que constitui o gênero.
\end{abstract}

PALAVRAS-CHAVE: gênero textual; causo; livro didático.

ABSTRACT: The textual genre "causo" has as its social communicative function, to incorporate Brazilian popular culture, therefore, being an important tool for preservation and dissemination of the present culture. Additionally, this work aims to discuss how this genre is proposed by the portuguese textbook, then, it was selected the book "Weaving languages" (OLIVERIA et al., 2012), for the 6th year of elementary school, besides, it has guided the research in the studies about the Socio-Discursive Interactionism (SDI). The results show that the material can't cover all the textual complexity, discursive and social communicative constituting the genre.

KEYWORDS: Text genre; “causo”; textbook.

\section{Introdução}

Com o intuito de tomar as operações de linguagem que constituem o gênero textual causo como objeto de ensino e aprendizagem na educação básica, como bolsistas do PIBID/UENP Letras/Português ${ }^{1}$, campus Jacarezinho, elaboramos um modelo didático do

1 O PIBID é o Programa Institucional de Bolsas de Iniciação à Docência subsidiado pedagógica e financeiramente pela Coordenação de Aperfeiçoamento de Pessoal do Ensino Superior - CAPES, e tem como 
gênero (STRIQUER E BATISTA, 2016). A partir do modelo foi possível a equipe do PIBID conhecer todos os elementos que compõem o referido gênero e então elaborar sequências didáticas destinadas aos sextos anos do ensino fundamental.

Assim, norteados pelas reflexões sobre as ações realizadas pela equipe de bolsistas na elaboração do modelo didático e na elaboração e implementação da sequência didática em quatro salas de aula dos sextos anos de escolas da rede pública de ensino, no ano de 2015, interessamo-nos em ampliar ainda mais nossa compreensão sobre o processo de ensino sobre o gênero, buscando, então, conhecer como o causo é tomado como objeto de ensino pelo livro didático que é um material muito mais presente nas salas de aula, de um modo geral, do que o trabalho com projetos. Assim, nosso objetivo é o de investigar como o livro didático de língua portuguesa organiza o processo de ensino do gênero causo. Para tanto, tomamos como base teórico-metodológica os preceitos do Interacionismo Sociodiscursivo (BRONCKART, 2009), buscando identificar quais e de que forma os elementos que constituem o gênero causo são abordados pelo livro didático.

O corpus de análise é o livro didático de língua portuguesa "Tecendo linguagens", de Oliveira et al (2012), destinado ao 6 ano do ensino fundamental.

\section{Fundamentação teórica}

De acordo com Bakhtin (2003), o uso da língua se concretiza por meio de enunciados individuais e únicos, e "cada campo de utilização da língua elabora seus tipos relativamente estáveis de enunciados" (p. 262). Enunciados definidos como gêneros do discurso, os quais caracterizam-se pelo conteúdo temático que refere-se ao que "é que pode ser dizível nos textos pertencentes a um gênero" (BRASIL, 1998, p. 21); pelo estilo que refere-se aos recursos linguísticos empregados em um texto: expressões, ordem da frase, conjunções, elementos coesivos, marcas enunciativas do produtor do texto, entre outros; e pela construção composicional, a qual relaciona-se com a estrutura interna dos textos: estrutura narrativa, dissertativa, explicativa, descritiva, injuntiva; pelo plano geral; e pelos tipos de discurso que formam o texto.

Defende ainda Bakhtin (2003) que a escolha de um ou de outro gênero é determinada pelas necessidades comunicativas dos interlocutores, visto que todo gênero discursivo/textual reflete o a situação comunicativa da qual está envolvido. Logo, existem infinitos gêneros. E, devido a essa grande variedade, Bakhtin (2003) classifica os gêneros do discurso em dois grupos: gêneros primários: correspondem aos gêneros mais espontâneos, mais simples que se originam do cotidiano. Exemplos: conversa informal entre amigos, bilhetes pessoais, entre outros. E os gêneros secundários, que são mais elaborados, complexos, uma vez que são desenvolvidos em convívios culturais mais formais. Exemplos: dicionários, romances, conferências acadêmicas, entre outros.

De acordo com essas definições, expomos a seguir, como constitui-se o gênero causo.

\section{O gênero textual causo}

objetivo proporcionar que os alunos dos cursos de licenciatura tenham contato direto com a educação básica, aprimorando a formação de ambos níveis de ensino. O Subprojeto Letras/Português, integrante do PIBID, vincula-se a Universidade Estadual do Norte do Paraná - UENP, campus Jacarezinho, e atende alunos dos 6 anos do ensino fundamental e dos 3 anos do ensino médio, tendo como eixo teórico-metodológico organizador os preceitos do Interacionismo Sociodiscursivo sobre gêneros discursivos/textuais e seu ensino. 
Baseados no modelo didático elaborado por Striquer e Batista (2016), apresentamos os elementos que caracterizam o gênero causo.

Segundo Gedoz e Costa-Hübes (2011) o causo é um gênero textual que tem como função sócio-comunicativa materializar a cultura popular brasileira, sendo, assim, importantíssimo instrumento para preservação e disseminação cultural. São histórias, geralmente, passadas de geração a geração, originariamente por meio da oralidade.

De acordo com o agrupamento de gêneros sugerido por Dolz, Noverraz e Schneuwly (2004), o causo pertence ao domínio social de comunicação da cultura ficcional literária; tem como capacidade de linguagem dominante o narrar fatos ficcionais ou verídicos do cotidiano, marcando uma construção textual espontânea, característica da linguagem oral, mesmo que com o passar do tempo tenham sido retextualizados para a modalidade escrita da língua.

O conteúdo temático (BAKHTIN, 2003) do causo é marcado por retratar acontecimentos e costumes próprios de pessoas que vivem em lugarejos, sítios, cidades do interior de certas regiões do Brasil, bem como do universo particular dos contadores.

Sobre os elementos que compõem o contexto de produção dos causos, conforme Bronckart (2009): o autor ou produtor do causo caracteriza-se como um dos participantes da história contada, como um personagem/narrador ou testemunha dos acontecimentos, visto que o autor do causo pretende dar sempre um cunho de verdade à história, por mais fantástica, insólita ou inacreditável que ela possa parecer; o leitor/ouvinte, sempre considerado na construção dos sentidos de um texto, é o visto pelo autor como aquele sujeito interessado em narrativas breves, humorísticas ou aterrozirantes que valorize a tradição popular de uma região; Sobre o momento de produção, ele está sempre ligado a memórias do contador, de momentos que ele viveu ou de momentos que ele ouviu histórias de parentes, amigos, conhecidos de lugares que acabam sendo propícios para a construção de histórias fantásticas.

O plano geral (BRONCKART, 2009), no caso em que os causos assumiram a forma escrita da língua, é formado por título e texto propriamente dito. Já se considerarmos a versão oral, o título, geralmente, não é constitutivo do gênero, o contador vai logo dando início à história sem a necessidade de apresentar um título. Sobre os tipos de sequências, a narrativa é predominante, porém é comum o emprego da sequência dialogal e da descritiva.

Sobre os demais elementos que compõem a narrativa do causo, destacamos o tempo e o espaço como basilares na composição desse gênero. O lugar do acontecimento narrado é, geralmente, mencionado pelo autor. As histórias aconteceram ou em um ambiente rural ou em cidades interioranas, espaços esses muito característicos do gênero em estudo. E o tempo é referenciado com expressões como: "há muitos anos", "quando eu era criança", etc, elementos que ajudam a contar o vivido ou o que foi ouvido pelo contador, ou são empregados para dar mais veracidade às histórias (BATISTA, 2007).

Outro elemento que caracteriza a narrativa são os personagens, no causo, geralmente, são pessoas conhecidas do autor, ou ele mesmo testemunha os acontecimentos, ou também podem ser animais ou seres sobrenaturais, como lobisomens e assombrações, para que a história possa receber elementos cômicos ou trágicos (BATISTA, 2007).

Sobre os mecanismos de textualização, segundo Batista (2007), destaca-se a coesão verbal, a qual realiza-se pelos emprego dos tempos verbais que asseguram a organização temporal e hierárquica dos acontecimentos. A predominância no causo é o emprego do pretérito perfeito e imperfeito, o que se justifica diante do fato do contador narrar ações já ocorridas. E, no que se refere aos mecanismos enunciativos, destacamos as vozes: a do próprio contador, assumindo, como define Bronckart (2009), a responsabilidade do que é enunciado; e a voz dos personagens que se realiza por meio do emprego do discurso direto.

De acordo com os conceitos de Bakhtin (2003), Gedoz e Costa-Hübes (2011), o causo pode ser classificado como, originalmente, um gênero primário, já que pertence ao grupo dos gêneros narrativos da tradição oral, pois emerge de situações de comunicação verbais espontâneas e informais. Uma vez transposto para a escrita, adquire características dos 
gêneros secundários, por obedecer à uma maior complexidade da norma culta na construção da sintaxe do texto.

É a partir de todas essas características específicas do gênero causo que analisamos o livro didático corpus de nossa pesquisa.

\section{Em foco o livro didático}

Do LD "Tecendo linguagens", de Oliveira et al, destinado ao 6 ano do ensino fundamental - língua portuguesa, analisamos o Capítulo I, momento em que o livro aborda o gênero causo como objeto de ensino e aprendizagem, e o qual se estrutura da seguinte forma: Seção "Pra começo de conversa" - propõe um trabalho de ativação do conhecimento prévio a respeito do gênero; Seção "Prática de leitura" - apresenta três diferentes exemplares de causos; Seção "Por dentro do texto" - formada por questões de estudo dos textos; Seção "Reflexão sobre o uso da língua" - toma como objeto de estudo recursos linguísticosgramaticais, no caso, o verbo; Seção "Na trilha da oralidade" - essa seção, diferente das demais, só aparece no final do capítulo seguida da Seção "Produção de texto" - que também é única e tem a função de orientar o aluno para a produção textual do gênero em trabalho no Capítulo. A seguir explicitamos os resultados das análises.

A função sócio-comunicativa de materializar a cultura popular brasileira é tomada como objeto de ensino em diferentes momentos no capítulo. Sendo a cultura popular brasileira representativa também do homem do campo e/ou de uma região do país localizada no interior dos estados, homem esse que utiliza de uma variante linguística chamada de caipira, essa característica é abordada pelo material, conforme sintetizamos no quadro 1 :

\begin{tabular}{|c|c|c|}
\hline & Seção & Trecho-exemplo \\
\hline Exemplo 1 & $\begin{array}{l}\text { "Pra } \\
\text { começo de } \\
\text { conversa" }\end{array}$ & $\begin{array}{l}\text { "2. A personagem representada na foto vive num ambiente rural } \\
\text { onde é comum as pessoas contarem histórias, em volta da fogueira, } \\
\text { perto do fogão a lenha. Pense em uma história que ela poderia contar. } \\
\text { Que tipo de história seria essa?” (OLIVERIA et al., 2012, p. 166) }\end{array}$ \\
\hline Exemplo 2 & $\begin{array}{l}\text { "Por dentro } \\
\text { do texto" }\end{array}$ & $\begin{array}{l}\text { "3. O narrador, além de mostrar ao leitor os causos de seu Ico, } \\
\text { retrata-o como uma personagem bem interiorana. Destaque palavras, } \\
\text { expressões ou frases que identifiquem seu Ico como tal." (p. 168) }\end{array}$ \\
\hline Exemplo 3 & $\begin{array}{l}\text { "Por dentro } \\
\text { do texto" }\end{array}$ & "c. O falar caipira pode ser considerado erro? Por quê? (p. 168) \\
\hline Exemplo 4 & $\begin{array}{l}\text { "Por dentro } \\
\text { do texto" }\end{array}$ & $\begin{array}{l}\text { "1. Observe a maneira como seu Ico fala. Lendo as frases destacadas } \\
\text { no texto na cor verde, a fala de seu Ico está de acordo com a fala de } \\
\text { quem foi criado na cidade grande ou no campo?" (OLIVERIA et al, } \\
2012 \text {, p. 169). }\end{array}$ \\
\hline Exemplo 5 & $\begin{array}{l}\text { "Por dentro } \\
\text { do texto" }\end{array}$ & $\begin{array}{l}\text { “... os causos são histórias de tradição oral, contadas, geralmente, em } \\
\text { uma linguagem espontânea, que registra o jeito de falar típico de } \\
\text { determinada região ou localidade." (p. 169). }\end{array}$ \\
\hline Exemplo 6 & $\begin{array}{l}\text { "Por dentro } \\
\text { do texto" }\end{array}$ & $\begin{array}{l}\text { "No texto, seu Ico conta seus causos, em uma linguagem que busca } \\
\text { representar o jeito de falar próprio de certas regiões do interior de São } \\
\text { Paulo: o falar caipira." (p. 169). }\end{array}$ \\
\hline Exemplo 7 & $\begin{array}{l}\text { "Por dentro } \\
\text { do texto" }\end{array}$ & $\begin{array}{l}\text { "Você conhece alguém que goste de contar causos, histórias } \\
\text { divertidas ou assustadoras? Se conhece, como é o jeito como essa } \\
\text { pessoa fala? Ela usa uma linguagem parecida com a linguagem usada } \\
\text { pelas pessoas do campo ou da cidade? Converse com o professor e os } \\
\text { colegas." (p. 170). }\end{array}$ \\
\hline
\end{tabular}




\begin{tabular}{|l|l|l|l|}
\hline Exemplo 8 & $\begin{array}{l}\text { "Reflexão } \\
\text { sobre o uso } \\
\text { da língua" }\end{array}$ & $\begin{array}{l}\text { "a) Que palavras do texto buscam representar o jeito do falar } \\
\text { caipira?" (p. 173). }\end{array}$ \\
\hline
\end{tabular}

Quadro 1: A função sócio-comunicativa do gênero como objeto de ensino

O primeiro exemplo do Quadro 1 faz referência a uma foto do ator Mazzaropi, caracterizado como Jeca Tatu, um personagem bastante conhecido no Brasil nas décadas de 1950 a 1960, que representa o homem do campo em sua essência mais caipira. A questão liga o causo ao ambiente rural onde, portanto, culturalmente, histórias são contadas. Além do exemplo 1, todos os demais transcritos no Quadro 1 evidenciam o emprego da variante popular, ou chamada de caipira, nos causos, os quais são originários do campo e do interior pela marcação explícita das expressões "ambiente rural"; personagem "interiorana"; "falar caipira"; "criado no campo"; "o jeito de falar próprio de certas regiões do interior", retiradas os exemplos expostos no Quadro 1.

Os exemplos que formam o Quadro 1 evidenciam ainda que o conteúdo temático do gênero causo de ser formado por acontecimentos e costumes próprios de pessoas que vivem nas cidades do interior de certas regiões do Brasil também é conteúdo de ensino e aprendizagem no LD.

Sobre os elementos que compõem o contexto de produção (BRONCKART, 2009), o autor desse gênero, como posto, caracteriza-se como aquele que é um dos participantes do enredo ou testemunha dos acontecimentos, o que é tratado pelo LD no texto de apresentação do terceiro exemplar do gênero:

Agora leia e divirta-se com o próximo texto escrito pelo grande escritor gaúcho Mário Quintana. Ele retrata, de forma bem-humorada, o espanto e a reação da população de uma pequena cidade diante da chegada inesperada de 'um bicho estranho': o automóvel. Trata-se de uma história curta, repleta de palavras e expressões típicas do Rio Grande do Sul. [...] (OLIVEIRA et al., 2012, p. 177).

O autor Mário Quintana é quem, segundo o LD, retrata o que ocorreu na história, ele é gaúcho, ou seja, tem origem no Rio Grande do Sul e a história se passa em uma cidade do interior desse estado. Assim, o autor é posto como o narrador-personagem da história, o que pode ser comprovado pelo emprego da primeira pessoa do discurso no texto: "Eu não afirmo nada: sou neutro"; "Mas, pelo que me contaram..."; A história foi assim como já lhes conto, ...” (OLIVERIA et al., 2012, p. 177). Em outras duas questões de estudo do texto essa característica do autor como narrador-personagem é também abordada, conforme Quadro 2:

\begin{tabular}{|l|l|l|}
\hline & Seção & Trecho-exemplo \\
\hline Exemplo 1 & $\begin{array}{l}\text { "Por dentro } \\
\text { do texto" }\end{array}$ & $\begin{array}{l}\text { "2. O narrador do causo ora se apresenta como uma personagem da } \\
\text { história, ora se apresenta como alguém que apenas observa a cena } \\
\text { (narrador-observador) sem estar envolvido nos acontecimentos. } \\
\text { Localize no texto o que se pede. } \\
\text { a) um trecho que comprova a participação do narrador na história. } \\
\text { b) um trecho em que o narrador aparece como observador." } \\
\text { (OLIVERIA et al., 2012, p. 178). }\end{array}$ \\
\hline Exemplo 2 & $\begin{array}{l}\text { "Prática de } \\
\text { leitura" } \\
\text { "2. Compare agora a estrutura dos dois textos. Copie em se caderno só } \\
\text { os aspectos que são comuns a ambos os textos. } \\
\text { c) O narrador envolvido na história". (p. 175) }\end{array}$ \\
\hline
\end{tabular}


Quadro 2: O narrador como participante do enredo ou testemunha dos acontecimentos narrados

O aspecto do causo poder ser uma história real ou ficcional também é conteúdo do LD, como sintetizamos no Quadro 3:

\begin{tabular}{|l|l|l|}
\hline & Seção & Trecho-exemplo \\
\hline Exemplo 1 & $\begin{array}{l}\text { "Por dentro } \\
\text { do texto" }\end{array}$ & $\begin{array}{l}\text { "Os causos são histórias de tradição oral, contadas, geralmente, em } \\
\text { uma linguagem espontânea, que registra o jeito de falar típico de } \\
\text { determinada região ou localidade. Envolvem fatos pitorescos, reais, } \\
\text { fictícios ou ambos; e podem ou não envolver o narrador." (p. 169) }\end{array}$ \\
\hline Exemplo 2 & $\begin{array}{l}\text { "Por dentro } \\
\text { do texto" }\end{array}$ & $\begin{array}{l}\text { "1. Você acha que essa história poderia ter ocorrido na realidade? Por } \\
\text { quê? (p. 179) }\end{array}$ \\
\hline \multicolumn{2}{|c|}{ Quadro 3: O tratamento sobre a história caracterizada como sendo fictícia ou real }
\end{tabular}

Porém, nessa caracterização do causo poder ser uma história de ficção, o LD expõe uma confusão entre o que é causo e o que é lenda. Em uma nota explicativa intitulada "Importante saber", descreve o material que "O texto 'O contador de causo' fala sobre os seres criados pela rica imaginação popular: o saci, a mula sem cabeça, o lobisomem. As histórias que contam fatos sobre esses seres são chamadas lendas" (OLIVERIA et al., 2012, p.168). "O contador de causo" como o próprio título anuncia é um causo, o qual pode trazer como personagens seres sobrenaturais que povoam as lendas, como os citados, contudo, ele é um gênero específico e a lenda que também é formada por personagens como o saci, a mula sem cabeça é um outro gênero, ou seja, o causo e lenda são dois gêneros distintos.

Uma outra característica do causo trabalhada pelo LD é o humor. Exemplo:

\begin{tabular}{|l|l|l|}
\hline & Seção & Trecho-exemplo \\
\hline Exemplo 1 & $\begin{array}{l}\text { "Por dentro } \\
\text { do texto" }\end{array}$ & $\begin{array}{l}\text { "Os contadores de causos apresentam vários recursos que costumam } \\
\text { prender a atenção de seus ouvintes, como entonação, gestos, } \\
\text { suspense, efeitos de surpresa, humor, etc." (OLIVERIA et al., 2012, } \\
\text { p. 169) }\end{array}$ \\
\hline Exemplo 2 & $\begin{array}{l}\text { "Prática de de } \\
\text { leitura" }\end{array}$ & $\begin{array}{l}\text { "2. Compare agora a estrutura dos dois textos. Copie em seu caderno } \\
\text { só os aspectos que são comuns a ambos os textos. } \\
{[\ldots]} \\
\text { [) Humor } \\
\text { e) Um título que expressa o humor no texto. (p. 176) }\end{array}$ \\
\hline
\end{tabular}

Quadro 4: O humor que configura o gênero

E o aspecto do causo ser formado pela tradição oral de contar histórias (GEDOZ E COSTA-HÜNES, 2011) é abordado pelo material de forma representativa, exemplos:

\begin{tabular}{|l|l|l|}
\hline & Seção & Trecho-exemplo \\
\hline Exemplo 1 & $\begin{array}{l}\text { "Por dentro } \\
\text { do texto" }\end{array}$ & $\begin{array}{l}\text { "1. Observe a maneira como seu Ico fala. Lendo as frases destacadas } \\
\text { no texto na cor verde, a fala de seu Ico está de acordo com a fala de } \\
\text { quem foi criado na cidade grande ou no campo?" (OLIVERIA et al, } \\
\text { 2012, p. 169). }\end{array}$ \\
\hline Exemplo 2 & $\begin{array}{l}\text { "Por dentro } \\
\text { do texto" }\end{array}$ & $\begin{array}{l}\text { “... os causos são histórias de tradição oral, contadas, geralmente, em } \\
\text { uma linguagem espontânea, que registra o jeito de falar típico de } \\
\text { determinada região ou localidade." (p. 169). }\end{array}$ \\
\hline
\end{tabular}




\begin{tabular}{|l|l|l|}
\hline Exemplo 3 & $\begin{array}{l}\text { "Por dentro } \\
\text { do texto" }\end{array}$ & $\begin{array}{l}\text { "No texto, seu Ico conta seus causos, em uma linguagem que busca } \\
\text { representar o jeito de falar próprio de certas regiões do interior de São } \\
\text { Paulo: o falar caipira. Esse falar não é registrado na escrita } \\
\text { exatamente da mesma maneira como povo emprega, pois um texto } \\
\text { escrito não consegue reproduzir como as pessoas falam; apenas o } \\
\text { representa" (p. 169). }\end{array}$ \\
\hline Exemplo 4 & $\begin{array}{l}\text { "Produção } \\
\text { de texto" }\end{array}$ & $\begin{array}{l}\text { "Você se lembra das palavras e expressões típicas das conversações } \\
\text { espontâneas, como: eu, acho que, aí, né, então, viu etc? Elas podem } \\
\text { ser usadas em seu texto, na fala das personagens, para fazer com que } \\
\text { se aproximem do jeito de falar usado em situações desse tipo." (p. } \\
\text { 181). }\end{array}$ \\
\hline
\end{tabular}

Quadro 5: A tradição oral dos causos

Os exemplos mostram o causo como sendo um gênero essencialmente constituída da oralidade, tanto é que o exemplo 4 leva o aluno a compreender que mesmo nos causos transcritos para a escrita, a marca principal é a modalidade oral da língua. E também outros elementos que marcam a oralidade são objeto de ensino no LD, exemplos:

\begin{tabular}{|l|l|l|}
\hline & Seção & Trecho-exemplo \\
\hline Exemplo 1 & $\begin{array}{l}\text { "Por dentro } \\
\text { do texto" }\end{array}$ & $\begin{array}{l}\text { "As marcas da linguagem oral não se restringem às palavras. Outros } \\
\text { recursos costumam fazer parte dela, como gestos, expressões faciais, } \\
\text { olhar, risos, pausas, movimentos de cabeça do falante. Esses recursos } \\
\text { podem ser empregados para tornar a comunicação mais eficiente." } \\
\text { (OLIVERIA et al., 2012, p. 170). }\end{array}$ \\
\hline Exemplo 2 & $\begin{array}{l}\text { "Por dentro } \\
\text { do texto" }\end{array}$ & $\begin{array}{l}\text { "7. Os gestos, a entonação da voz, o jeito de olhar, as pausas e risadas } \\
\text { são importantes para um contador? Por quê?" (p. 170). }\end{array}$ \\
\hline Exemplo 3 & "Produção & $\begin{array}{l}\text { "O narrador pode relatar os gestos e as expressões faciais das } \\
\text { personagens... Esse recurso torna a cena mais viva para o leitor. No } \\
\text { texto "O contador de causo", por exemplo, o narrador conta como foi o } \\
\text { riso da personagem e indica sua expressão nesse momento: "Dá uma } \\
\text { gargalhada rouca e faz um ar maroto." (p. 181). }\end{array}$ \\
\hline
\end{tabular}

Quadro 6: A modalidade oral da língua

Esses recursos de gesticular, de entonar a voz demonstram a intensidade da fala, a espontaneidade e a busca de dar veracidade aos fatos pelo narrador, como se o próprio contador estivesse, sempre lá, no momento do ocorrido, buscando assim uma proximidade do narrador com seu interlocutor.

Contudo, apesar de todos esses elementos específicos do gênero serem tomados como objeto de ensino e aprendizado pelo livro didático, alguns outros são abordados de forma problemática, como é o caso da confusão entre tratar o causo e lenda como um único gênero, conforme já discutido, e outros que não desconsiderados pelo material.

Por exemplo, sobre o leitor, elemento que forma as condições de produção do gênero, somente ao final do capítulo, na seção destinada a "Produção do texto", a obra encaminha o aluno a considerar, no momento da produção de seu texto, quem será o leitor, não abordando assim o caráter participativo do interlocutor conforme define Bakhtin (2003), na construção dos sentidos dos exemplares oferecidos durante o capítulo.

Outros problemas podem ser identificados na proposta de trabalho já com a arquitetura textual do causo (BRONCKART, 2009), como o que ocorre com a sequência narrativa que é a predominante nesse gênero, e com as sequências dialogais e descritivas também características do causo. A obra não traz nenhuma informação a respeito dessa organização, tampouco dos elementos que formam a narrativa: tempo e espaço, os quais poderiam ser 
trabalhados no estudo dos exemplares que formam o capítulo. O primeiro exemplar do causo, intitulado "Num rancho às margens do Rio Pardo", de autoria da Equipe Xico da Kafua, tem como espaço da narrativa o referido rancho localizado em uma cidade do interior do Estado de São Paulo, Cajuru. E, a história do terceiro exemplo "Aquele animal estranho", de Mário Quintana, acontece em Alegrete, cidade do interior do Rio Grande do Sul. Ou seja, o espaço onde ocorrem a história são importantes características desse gênero (STRIQUER E BATISTA, 2016) e no momento de estudo desses exemplares seria uma oportunidade dessas especificidades ser abordadas pelo material, o que não ocorre.

Também no causo "Num rancho às margens do Rio Parde" os personagens dialogam, exemplo:

-Mas era assombração mesmo, seu Ico?

-Pois a que havera di sê? Esse mundo é surtido!

Pois no mundo sortido do seu Ico também tinha saci!

-Quando é que o senhor viu saci, seu Ico? (OLIVEIRA et al., 2012, p. 167).

Mas a referida sequencia dialogal não é trabalhada pelo material.

Vale destacar também que no momento do trabalho com o verbo, na seção "Reflexão sobre o uso da língua", seria possível fazer uma relação do tempo verbal predominantemente empregado no texto com a organização da sequência narrativa. Porém, o que ocorre é uma abordagem pelo LD que pode ser considerada tradicionalista. De acordo com Batista (2007), no gênero causo é muito recorrente o emprego do tempo verbal do pretérito perfeito e do imperfeito, visto que as ações narradas já ocorreram. Contudo, o material não relaciona o verbo como um elemento que organiza o discurso no texto, o faz o considerando como um recurso gramatical desvinculado dos textos que formam o capítulo, apenas retirando frases para exemplificação da definição conceitual. Exemplos:

\begin{tabular}{|c|c|c|c|c|c|c|}
\hline & Seção & \multicolumn{5}{|l|}{ Trecho-exemplo } \\
\hline Exemplo 1 & $\begin{array}{l}\text { "Reflexão } \\
\text { sobre o uso } \\
\text { da língua" - } \\
\text { referente ao } \\
\text { texto } 1\end{array}$ & \multicolumn{5}{|c|}{$\begin{array}{l}\text { "1. Observe a frase a seguir: } \\
\text { [...] o saci-pai acendeu o cigarro de palha dele. } \\
\text { a) Que ação é apresentada no trecho destacado? } \\
\text { b) Quem pratica essa ação? } \\
\text { c) O fato relatado já ocorreu ou está ocorrendo? Como você chegou a } \\
\text { essa conclusão? } \\
\text { 2. Observe o tempo dos verbos no trecho a seguir: } \\
\text { E mula sem cabeça? Ah, seu Ico garante que existe [...] } \\
\text { a) Eles estão no presente, no passado ou no futuro? } \\
\text { b) Por que o narrador empregou esse tempo do verbo nesse trecho? } \\
\text { 3. Vamos relembrar algumas características do verbo, estudado no } \\
\text { capítulo anterior. } \\
\text { Os verbos sofrem variações de acordo com o tempo e com as } \\
\text { pessoas do discurso aos quais estão relacionados. } \\
\text { (OLIVEIRA et al., 2012, p. 171). }\end{array}$} \\
\hline \multirow[t]{4}{*}{ Exemplo } & \multirow{4}{*}{$\begin{array}{l}\text { "Reflexão } \\
\text { sobre o uso } \\
\text { da língua" - } \\
\text { referente ao } \\
\text { texto } 2\end{array}$} & \multicolumn{5}{|c|}{$\begin{array}{l}\text { "2. Releia o texto 'O defunto vivo'. Da lista de verbos a seguir, copie } \\
\text { em seu caderno aqueles que não expressam ideia de tempo, ou seja, } \\
\text { aqueles que não localizam os fatos no tempo. }\end{array}$} \\
\hline & & Entregou/abrigar & Levava & Pediu & Respondeu & Correndo \\
\hline & & Chover & Dirigir & & & \\
\hline & & \multicolumn{5}{|c|}{ a) Agora verifique se as palavras que você copiou podem ser } \\
\hline
\end{tabular}




\begin{tabular}{|l|l|}
\hline & $\begin{array}{l}\text { localizadas no dicionário. } \\
\text { b) As palavras que não foram copiadas podem ser localizadas no } \\
\text { dicionário da maneira como estão escritas? Como você as encontra } \\
\text { no dicionário?" (p.176). }\end{array}$ \\
\hline
\end{tabular}

Quadro 7: O trabalho com o verbo

Em relação ao emprego de vozes dos personagens (BRONCKART, 2009) como mecanismos enunciativos que caracterizam o gênero (STRIQUER E BATISTA, 2016), as quais são marcadas pelo uso do discurso direto, em apenas um questão de todo o capítulo o livro toma esse recurso linguístico-discursivo como objeto de ensino, da seguinte forma:

1.Compare agora a estrutura dos dois textos. Copie em seu caderno só os aspectos que são comuns a ambos os textos.

$[\ldots]$

f) fala dos personagens. (OLIVEIRA et al., 2012, p. 176)

Logo, fica aparente que nada é abordado sobre como a fala dos personagens é construída, a estrutura formal do discurso direto não é trabalhada.

\section{Considerações finais}

Os resultados das análises realizadas sobre o livro didático "Tecendo linguagens", (OLIVEIRA et al, 2012) demonstram que a obra não consegue abranger toda a complexidade textual, discursiva e enunciativa que constitui o gênero textual causo. $\mathrm{O}$ material toma como conteúdo de ensino e aprendizagem alguns das características do gênero, como a função sócio-comunicativa; o emprego da variante caipira; um dos elementos que formam o conteúdo temático, o autor do causo como participante do enredo; o fato das histórias poderem ser reais, mas com traços profundos da ficção; o humor; e os traços da oralidade, mesmo nos causos da modalidade escrita da língua.

Contudo, o livro apresenta um problema de ordem conceitual confundindo causo com lenda; o leitor não é posto como constitutivo para a construção dos sentidos do texto; não existem atividades para o trabalho com as sequências que organizam o conteúdo temático: a sequência narrativa, a dialogal e a descritiva; o verbo é um elemento da língua visto de forma tradicionalista-gramatical; e as vozes não são objeto de ensino.

Nesse sentido, compreendemos que a obra, pelo que ela proporciona no trabalho com o gênero causo, pode ser considerada um importante instrumento pedagógico, no entanto, caberá ao professor elaborar ações didáticas e atividades para que o aluno conheça todas as operações de linguagem que formam o gênero e assim possa desenvolver práticas de leitura e de escrita do causo.

\section{Referências}

BAKHTIN, Mikhail. Estética da Criação Verbal. Tradução de Maria E. Galvão. 3 ed. São Paulo: Martins Fontes, 2003. 
BATISTA, Gláucia Aparecida. Entre causos e contos: gêneros discursivos da tradição oral numa perspectiva transversal para trabalhar a oralidade, a escrita e a construção da subjetividade na interface entre a escola e a cultura popular. 2007. (Dissertação de Mestrado) Programa de Pós-Graduação em Linguística Aplicada. Universidade de Taubaté, São Paulo, 2007.

BRASIL. Secretaria de Educação Fundamental. Parâmetros curriculares nacionais: Língua Portuguesa. Brasília. Secretaria de Educação Fundamental, 1998.

BRONCKART, Jean-Paul. Atividade de Linguagem, textos e discursos: por um Interacionismo Sociodiscursivo. Tradução Anna Rachel Machado e Pericles Cunha. São Paulo: Educ, 2009.

DOLZ, Joaquim; NOVERRAZ, Michele; SCHNEUWLY, Bernard. Sequências didáticas para o oral e a escrita: apresentação de um procedimento. In: DOLZ, Joaquim; SCHNEUWLY, Bernard. Gêneros orais e escritos na escola. Tradução e organização Roxane Rojo e Glaís Sales Cordeiro. Campinas, SP: Mercado de Letras, 2004, p. 95-128.

DOLZ, Joaquim; SCHNEUWLY, Bernard. Gêneros e progressão em expressão oral e escrita: elementos para reflexões sobre uma experiência suíça (francófona). In: SCHNEUWLY, Bernard; DOLZ, Joaquim. Gêneros orais e escritos na escola. Tradução e organização Roxane Rojo e Glaís Sales Cordeiro. Campinas/SP: Mercado das Letras, 2004, p. 41-70.

GEDOZ, Sueli; COSTA-HÜBES, Terezinha da Conceição. O gênero discursivo causo: reflexões sobre sua caracterização a partir da teoria bakhtiniana. Travessias, Cascavel/PR, v. 5, n. 1, p. 1-18, 2011.

OLIVEIRA, Tania Amaral et.al Tecendo Linguagens: Língua Portuguesa. 3. ed. São Paulo: IBEP, 2012. Cap. 1. p. 165-181.

STRIQUER, Marilúcia dos Santos Domingos Striquer; BATISTA, Patrícia Cardoso. O gênero textual causo: um modelo didático. e-scrita. Revista do Curso de Letras da UNIABEU, v.7, n.1. Nilópolis/RJ, janeiro-abril, 2016, p.147-161. 